\title{
Induction of Anthranilate Synthase Activity by Elicitors in Oats
}

Tetsuya Matsukawa ${ }^{a, b, *}$, Atsushi Ishihara ${ }^{a, b}$ and Hajime Iwamura ${ }^{\mathrm{b}, \mathrm{c}}$

a Division of Applied Life Sciences, Graduate School of Agriculture, Kyoto University, Kyoto 606-8502, Japan. Fax: +81(75) 7536408. E-mail: tmatsu@kais.kyoto-u.ac.jp

b CREST, Japan Science and Technology Corporation (JST)

c Department of Bio-Technology, School of Biology-Oriented Science and Technology, Kinki University, Uchita-cho, Naga-gun, Wakayama 649-6493, Japan

* Author for correspondence and reprint requests

Z. Naturforsch. 57c, 121-128 (2002); received September 10/October 12, 2001

Anthranilate Synthase, Avenanthramide, Oats

Oat phytoalexins, avenanthramides, are a series of substituted hydroxycinnamic acid amides with anthranilate. The anthranilate in avenanthramides is biosynthesized by anthranilate synthase (AS, EC 4.1.3.27). Induction of anthranilate synthase activity was investigated in oat leaves treated with oligo- $N$-acetylchitooligosaccharide elicitors. AS activity increased transiently, peaking $6 \mathrm{~h}$ after the elicitation. The induction of activity was dependent on the concentration and the degree of polymerization of the oligo- $N$-acetylchitooligosaccharide elicitor. These findings indicate that the induction is part of a concerted biochemical change required for avenanthramide production. The elicitor-inducible AS activity was strongly inhibited by L-tryptophan and its analogues including 5-methyl-DL-tryptophan, and 5- and 6fluoro-DL-tryptophan, while the activity was not affected by D-tryptophan. The accumulation of avenanthramide A was also inhibited by treatment of elicited leaves with these AS inhibitors, indicating that a feedback-sensitive AS is responsible for the avenanthramide production. In elicited leaves, the content of free anthranilate remained at a steady, low level during avenanthramide production. Moreover, administration of anthranilate to elicited oat leaves resulted in an enhanced avenanthramide accumulation. AS may play a role as a ratelimiting enzyme in the biosynthesis of avenanthramides.

\section{Introduction}

Avenanthramides, a series of hydroxycinnamic acid amides with hydroxyanthranilates, have been well characterized as phytoalexins in oats (Mayama et al., 1981; 1982). Avenanthramides accumulate in oat leaves in incompatible interactions with crown rust fungus (Puccinia coronata f. sp. avenae), and are considered an important factor in the defense against pathogens. An accumulation of avenanthramides is also evoked by treatment of oat leaves with various elicitors including $N$ acetylchitooligosaccharides (Bordin et al., 1991).

The hydroxyanthranilate in avenanthramides has been demonstrated to be derived from anthranilate by feeding experiments with labeled precursors (Ishihara et al., 1999a). The hydroxycinnamoyl moieties have been shown to be biosynthesized via the phenylpropanoid pathway. The enzymes of this pathway are activated concertedly following elicitor treatment (Ishihara et al., 1999b). In addition, hydroxycinnamoyl-CoA:hydroxyanthanilate $N$-hydroxycinnamoyltransferase
(HHT, EC 2.3.1.-), which catalyzes the final condensation reaction to form the amide bond, was identified in elicitor-treated oat leaves (Ishihara et al., 1997; 1998). These findings indicate that avenanthramides are de novo synthesized from anthranilate and L-phenylalanine supplied by the shikimate pathway that branches at chorismate. Thus, the enzymes catalyzing the first steps from the branch point may have important regulatory functions for avenanthramide biosynthesis.

The first step leading to the biosynthesis of hydroxyanthranilate is catalyzed by anthranilate synthase (AS, EC 4.1.3.27). AS is involved in the biosynthesis of many secondary metabolites in plants, and is indicated to play a regulatory role in the biosynthesis of tryptophan (Delmer and Mills, 1968; Widholm, 1974). Plant AS has been demonstrated to be composed of two subunits, AS $\alpha$ and AS $\beta$, by enzyme purification (Poulsen et al., 1993; Bohlmann et al., 1995) and by cDNA cloning (Niyogi and Fink, 1992; Niyogi et al., 1993). AS $\alpha$ catalyzes the conversion of chorismate to anthranilate with ammonia as amino donor, while AS $\beta$ 
transfers the amino group from glutamine to AS $\alpha$. Genes encoding the $\alpha$-subunits of AS isozymes have been cloned from Arabidopsis (Niyogi and Fink, 1992) and Ruta graveolens (Bohlmann et al., 1995). The expression of a specific isozyme is induced by environmental stimuli, suggesting the involvement of the isozyme in the activated production of secondary metabolites in these plants.

To elucidate the function of AS in the biosynthesis of avenanthramides, the induction of AS by elicitor treatment was investigated in oat leaves. In addition, the elicitor-inducible AS was purified and characterized.

\section{Materials and Methods}

\section{Plant material}

Oat (Avena sativa L. cv. Shokan 1) caryopses were soaked in distilled water for $24 \mathrm{~h}$. They were then sown in wet vermiculite and maintained at $20^{\circ} \mathrm{C}$ for $7 \mathrm{~d}$ under continuous light $\left(15 \mathrm{~W} \mathrm{~m}^{-2}\right)$ in growth chambers. At this growth stage, the average height of seedlings was around $7 \mathrm{~cm}$. After the lower epidermis had been peeled off, primary leaves were floated on a solution of $1 \mathrm{~mm}$ oligo- $N$-acetylchitooligosaccharides as described previously (Ishihara et al., 1998).

\section{Chemicals}

Chorismic acid (barium salt) and $\beta$-phenylpyruvic acid were obtained from Sigma. Oligo- $N$-acetylchitooligosaccharides were purchased from Seikagaku Kogyo, Tokyo. All other chemicals were from Wako Pure Chemical Industries, Osaka.

\section{Buffers}

The following buffers were used for enzyme preparation and purification: Buffer A, $100 \mathrm{~mm}$ tris(hydroxymethyl)aminomethane (Tris)- $\mathrm{HCl}$ buffer ( $\mathrm{pH}$ 7.5) containing $1 \mathrm{~mm}$ EDTA, $2 \mathrm{~mm}$ mercaptoethanol, $20 \mathrm{~mm}$ glutamine, $4 \mathrm{~mm} \mathrm{MgCl}_{2}$ and $10 \%$ glycerol; Buffer B, $50 \mathrm{~mm}$ Tris- $\mathrm{HCl}$ buffer (pH 7.5) containing $1 \mathrm{~mm}$ EDTA, 2 mм mercaptoethanol, $20 \mathrm{~mm}$ glutamine, $4 \mathrm{~mm} \mathrm{MgCl}_{2}$ and $10 \%$ glycerol; Buffer C, 20 mm Tris- $\mathrm{HCl}$ buffer ( $\mathrm{pH} 7.5$ ) containing $1 \mathrm{~mm}$ EDTA, $2 \mathrm{~mm}$ mercaptoethanol, $20 \mathrm{~mm}$ glutamine, $4 \mathrm{~mm} \mathrm{MgCl}_{2}$ and $10 \%$ glycerol.

\section{Enzyme extraction}

All procedures were carried out at $4{ }^{\circ} \mathrm{C}$. Oat leaves ( $c a$. $0.25 \mathrm{gFW}$ ) were frozen in liquid nitrogen and ground until well powdered. The powder was extracted with 5 volumes of buffer $A$, and centrifuged for $10 \mathrm{~min}$ at $12,000 \times g$. The supernatant was passed over a PD-10 column (Pharmacia) equilibrated with buffer A to remove low molecular weight compounds. The fraction containing proteins was used for the enzyme assay as the crude extract. Protein concentration was determined by the method of Bradford (1976) using bovine serum albumin (BSA) as the protein standard.

\section{Enzyme assay}

Anthranilate synthase assay was carried out according to the method of Bücker et al. (1995) with a slight modification. A reaction mixture containing $0.5 \mathrm{ml}$ of $4 \mathrm{~mm}$ chorismate and $0.5 \mathrm{ml}$ of the crude extract was incubated at $30^{\circ} \mathrm{C}$ for $30 \mathrm{~min}$. The reaction was stopped by boiling water. Precipitated proteins were removed by centrifugation $(12,000 \times g, 30 \mathrm{~min})$, and the resulting supernatant was subjected to reversed-phase HPLC (column: Polymer C18, $150 \times 4.6 \mathrm{~mm}$, YMC, Kyoto). Anthranilate was eluted with $45 \%$ methanol in water containing $0.1 \%$ phosphoric acid at a flow rate of $0.8 \mathrm{ml} \mathrm{min}^{-1}$, and was detected with a fluorescence detector (Shimadzu RF-10AXL; Ex = $340 \mathrm{~nm}, \mathrm{Em}=400 \mathrm{~nm})$. In this system, anthranilate was eluted with a retention time of $15.2 \mathrm{~min}$.

\section{Partial purification of $A S$}

All operations were carried out at $4{ }^{\circ} \mathrm{C}$. A solution of $50 \%(\mathrm{w} / \mathrm{v})$ polyethylene glycol 6000 was added to the crude extract to give a final concentration of $5 \%$. After stirring for $30 \mathrm{~min}$, the precipitate was collected by centrifugation $(10,000 \times g, 30$ $\min )$. The supernatant was adjusted to a final concentration of $18 \%$ polyethylene glycol 6000 , and the precipitate was collected by centrifugation $(10,000 \times \mathrm{g}, 30 \mathrm{~min})$. The resulting pellet was dissolved in buffer B. This solution was subjected to preparative electrophoresis using a Mini Prep Cell (Bio Rad) instrument (elution buffer: buffer B, polyacrylamide gel: $5 \%, 5 \mathrm{~cm}, \mathrm{pH} 7.5$, constant current: $7.5 \mathrm{~mA}$ ). The active fractions were col- 
lected and applied to a Mono Q HR 5/5 column (Pharmacia) equilibrated with buffer C. AS was eluted with a $40 \mathrm{ml}$ linear gradient of 0 to $0.3 \mathrm{M}$ $\mathrm{NaCl}$ at a flow rate of $0.5 \mathrm{ml} / \mathrm{min}$. Fractions containing AS activity were concentrated by ultrafiltration (Centricon-10, Amicon), and finally loaded onto a Superdex 200 HR 10/30 column (Pharmacia) equilibrated with buffer B. Proteins were eluted with buffer $\mathrm{B}$ at a flow rate of 0.2 $\mathrm{ml} / \mathrm{min}$. For determination of the native molecular weight of the purified enzyme, transfer in ( $\mathrm{MW}=$ $81 \mathrm{kDa})$, BSA $(\mathrm{MW}=66 \mathrm{kDa})$, lactoglobin $(\mathrm{MW}=35 \mathrm{kDa})$, and myoglobin $(\mathrm{MW}=17.6 \mathrm{kDa})$ were used as molecular weight markers.

\section{Analysis of anthranilic acid and avenanthramides in elicitor-treated oat leaves}

For analysis of free anthranilic acid, elicitortreated oat leaves frozen in liquid nitrogen were ground until well powdered. After the addition of $p$-aminobenzoic acid as internal standard, the powder was extracted twice with 10 volumes of methanol. The solution was centrifuged for $10 \mathrm{~min}$ at $12,000 \times g$. The combined supernatant fraction was evaporated to dryness in vacuo. The residue was dissolved in $5 \mathrm{ml}$ of distilled water, and extracted twice with $5 \mathrm{ml}$ of ethyl acetate. The combined ethyl acetate phase was evaporated, and the residue was dissolved in $1 \mathrm{ml}$ of methanol. The solution was analyzed by reversed-phase HPLC under the same conditions described in the enzyme assay section.

The amounts of avenanthramides were determined by HPLC analysis of the elicitor solution $24 \mathrm{~h}$ after elicitation as described previously (Ishihara et al., 1998).

\section{Result}

\section{Induction of AS activity by elicitor treatment}

Changes in AS activity were investigated in leaves treated with penta- $N$-acetylchitopentaose [(GlcNAc) $\left.)_{5}\right]$ at $1 \mathrm{~mm}$ (Fig. 1A). At this concentration, a maximal amount of oat phytoalexins, avenanthramides, was found to accumulate in the elicitor solution (Ishihara et al., 1998). Some AS activity was detectable before elicitor treatment (0.27 fkat $/ \mathrm{mg}$ protein). In the treated leaves, AS activity started to increase $1-3 \mathrm{~h}$ after elicitation,
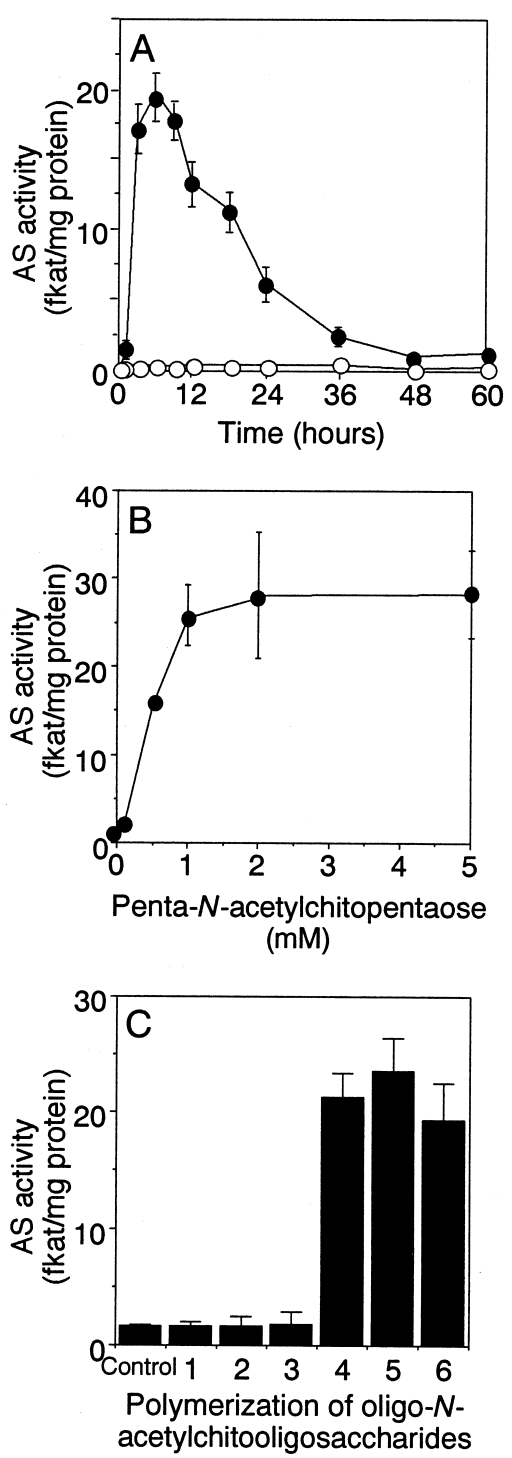

Fig. $1 \mathrm{~A}-\mathrm{C}$. Induction of AS activity by elicitation. A, Changes in AS activity following elicitor treatment. Oat leaves were floated on $1 \mathrm{~mm}$ penta- $N$-acetylchitopentaose (closed circles) or distilled water (open circles) at time 0 . B, Effects of concentration of penta- $N$-acetylchitopentaose on induction of AS activity. The AS activity was determined $9 \mathrm{~h}$ after elicitor treatment. C, Effects of degree of polymerization of oligo- $N$-acetylchitooligosaccharides on induction of AS activity. Oat leaves were treated with $1 \mathrm{~mm}$ oligo- $N$-acetylchitooligosaccharides for $9 \mathrm{~h}$. Each result is expressed as the mean of triplicate experiments $\pm \mathrm{SD}$.

and reached a maximum after $6 \mathrm{~h}(19.7 \mathrm{fkat} / \mathrm{mg}$ protein). Thereafter, it gradually decreased until $60 \mathrm{~h}$ after elicitation. In control leaves, AS activity 
remained unchanged even $60 \mathrm{~h}$ after peeling off of the lower epidermis.

Fig. 1B shows the effects of elicitor concentration on the induction of AS activity. The enzyme activity was determined $6 \mathrm{~h}$ after elicitation after having attained a maximal level. The activity increased along with elicitor concentrations up to 1 mm. At higher concentrations no further increase was observed.

The production of avenanthramides and the induction of biosynthetic enzyme activities strictly depend on the size of the oligo- $N$-acetylchitooligosaccharides (Ishihara et al., 1999b). The inducing activity of oligo- $N$-acetylchitooligosaccharides showed similar specificity (Fig. 1C). Oligosaccharides smaller than trisaccharides showed no elicitor activity. Pentasaccharide induced the enzyme activity most effectively, and tetra- and hexasaccharides also had a strong inducing activity.

\section{Partial purification of $A S$ in elicitor-treated leaves}

AS was partially purified from elicitor-treated leaves (Table I). The crude extract was subjected to four purification steps, i.e. polyethylene glycol precipitation, preparative electrophoresis, anion exchange chromatography, and gel filtration. The recovery after polyethylene glycol precipitation was more than $100 \%$, probably due to removal of some inhibitors. No separation of AS isozymes was detected by preparative electrophoresis, anion exchange chromatography, and gel filtration. AS from elicitor-treated leaves was purified 53-fold, and the final activity was around $1.0 \mathrm{pkat} / \mathrm{mg}$ protein. Enzyme assays were performed both for glutamine-dependent activity and for ammonia-dependent activity in order to monitor the loss of AS $\beta$ during purification. Both activities strictly coeluted in all chromatographies, and the ratio of glutamine-dependent activity to ammonia-depen- dent activity did not change; this ratio was found 1.31 with the crude extract and 1.36 with the purified enzyme. These results indicated that the purified AS contained $\alpha$ - and $\beta$-subunits. On the basis of gel filtration, the native molecular weight of the AS $\alpha \beta$ complex was estimated to be $113 \mathrm{kDa}$. No activity of chorismate mutase which accepts chorismate as a substrate and thus interferes with the estimation of the kinetic parameters of AS was detected in the purified enzyme.

\section{Characterization of AS from elicitor-treated leaves}

With the partially purified enzyme, the initial velocity of anthranilate formation was measured at various concentrations of chorismate and glutamine. The enzyme showed Michaelis-Menten kinetics with respect to the substrates, with the apparent $K_{\mathrm{m}}$ value for chorismate of $270 \mu \mathrm{M}$, and 790 $\mu \mathrm{M}$ for L-glutamine. The $\mathrm{pH}$ optimum was found at $\mathrm{pH} 7.5$.

L-Tryptophan, 5-methyl-DL-tryptophan, 5-fluoro-DL-tryptophan, and 6-fluoro-DL-tryptophan strongly inhibited the activity, while D-tryptophan, 5-hydroxy-DL-tryptophan, and 3-indoleacrylic acid did not show an inhibitory effect even at $5 \mathrm{~mm}$ (Table II). Since avenanthramide A and 5-hydroxyanthranilate are considered to be the major end-products of elicitor-inducible AS, they were included in the assay, but neither activation nor inhibition by these compounds was found.

The effect of tryptophan analogues on constitutively present AS was also investigated. Because this activity was quite low and unstable, the enzyme preparation purified from intact leaves by only polyethylene glycol precipitation and anion exchange chromatography was utilized to avoid loss of enzyme activity (Table II). The activity of constitutive AS was also strongly inhibited by tryptophan and its analogues, and the constitutive

Table I. Purification of AS from oat leaves treated with elicitor. Oat leaves were floated on $1 \mathrm{~mm}$ penta- $N$-acetylchitopentaose at $20^{\circ} \mathrm{C}$. After $9 \mathrm{~h}$ incubation, the leaves were extracted.

\begin{tabular}{lcccc}
\hline Purification step & $\begin{array}{c}\text { Total activity } \\
\text { (fkat) }\end{array}$ & $\begin{array}{c}\text { Protein } \\
\text { (mg) }\end{array}$ & $\begin{array}{c}\text { Specific activity } \\
\text { (fkat/mg protein) }\end{array}$ & $\begin{array}{c}\text { Purification } \\
\text { factor }\end{array}$ \\
\hline Crude extract & 1290 & 67 & 19.2 & - \\
Polyethylene glycol precipitation & 1340 & 28 & 48.0 & 2.5 \\
Mini Prep Cell & 424 & 0.63 & 673 & 35 \\
Mono Q & 366 & 0.37 & 988 & 51 \\
Superdex 200 & 111 & 0.11 & 1010 & 53 \\
\hline
\end{tabular}


Table II. Feedback inhibition of anthranilate synthase by tryptophan analogues, avenanthramide A, and 5-hydroxyanthranilate. AS was purified from oat leaves treated with $1 \mathrm{~mm}$ penta- $N$-acetylchitopentaose for $9 \mathrm{~h}$ and intact oat leaves. Each result represents the concentration of tryptophan analogues at which AS activity was $50 \%$ of that in the absence of the tryptophan analogues.

\begin{tabular}{lcc}
\hline Tryptophan analogue & \multicolumn{2}{c}{$50 \%$ Inhibitory level $[\mu \mathrm{M}]$} \\
\cline { 2 - 3 } & $\begin{array}{c}\text { Elicitor-inducible } \\
\text { AS }\end{array}$ & $\begin{array}{c}\text { Constitutive } \\
\text { AS }\end{array}$ \\
\hline L-Tryptophan & 4.6 & 2.0 \\
D-Tryptophan & $-{ }^{\mathrm{a}}$ & - \\
5-Methyl-DL-tryptophan & 3.8 & 2.1 \\
5-Fluoro-DL-tryptophan & 5.4 & 2.5 \\
6-Fluoro-DL-tryptophan & 8.5 & 3.1 \\
5-Hydroxy-DL-tryptophan & - & - \\
3-Indoleacrylic acid & - & n.d. \\
Avenanthramide A & - & - \\
5-Hydroxyanthranilate & - & - \\
\hline
\end{tabular}

a - ; not inhibited over $5 \mathrm{~mm}$.

$\mathrm{b}$ n.d.; not determined.

AS was somewhat more sensitive to these compounds than the elicitor-inducible AS.

\section{Effects of tryptophan analogues on avenanthramide accumulation}

Oat leaf segments were treated with $1 \mathrm{~mm}$ $(\mathrm{GlcNAc})_{5}$ in the presence of L-tryptophan, 5methyl-DL-trypotophan, and D-tryptophan at various concentrations. After a 24-h incubation, the amount of avenanthramide A was determined. The accumulation of avenanthramide $\mathrm{A}$ was markedly inhibited by L-tryptophan and 5-methylDL-tryptophan in a dose-responsive manner (Fig. 2). In the presence of $500 \mu \mathrm{M}$ L-tryptophan or 5-methyl-DL-tryptophan, the respective amounts of avenanthramide $\mathrm{A}$ were $10 \%$ and $3 \%$ of the amount accumulated in the absence of these inhibitors. In contrast, D-tryptophan that had no effect on AS activity showed no inhibitory effect on the accumulation of avenanthramide $A$ even at $500 \mu \mathrm{M}$.

The presence of L-tryptophan in the elicitor solution did not affect the induction of AS activity. The level of AS activity in the leaves treated with $1 \mathrm{~mm}$ (GlcNAc) $)_{5}$ for $6 \mathrm{~h}$ in the presence of $500 \mu \mathrm{M}$ L-tryptophan (19.7 fkat/mg protein) was almost the same as that in the leaves treated with the elicitor without L-tryptophan (21.2 fkat/mg protein).

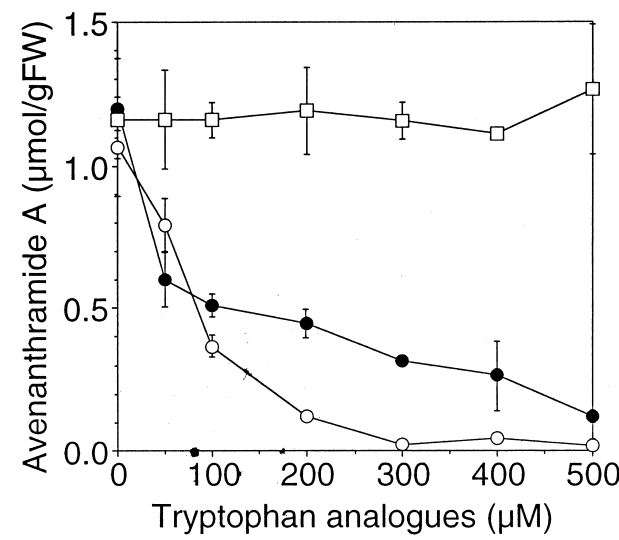

Fig. 2. Effects of tryptophan analogues on the accumutaion of avenanthramide A. Oat leaf segments were floated on the $1 \mathrm{~mm}$ penta- $N$-acetylchitopentaose solution containing various concentrations of L-tryptophan (closed circle), 5-methyl-DL-tryptophan (open circle), and D-tryptophan (open square). After a 24-h incubation, amounts of avennanthramide A were determined. The results are expressed as the means of triplicate experiments \pm SD.

\section{Effects of anthranilate and phenylalanine on avenanthramide accumulation}

In view of the possibility that AS acts as a ratelimiting enzyme in the biosynthesis of avenanthramides, anthranilate was administered to the leaves treated with $1 \mathrm{~mm}$ (GlcNAc) $)_{5}$, and amounts of avenanthramide A were determined (Fig. 3). Since the hydroxycinnamic acids in avenanthramides are derived from L-phenylalanine, the effects of the application of L-phenylalanine were also examined. The amount of avenanthramide A increased along with the anthranilate concentration up to $50 \mu \mathrm{M}$. The maximal amount of avenanthramide A was around 2.7-fold that accumulated in the absence of exogenious anthranilate. At higher concentrations, the amount of avenanthramide A decreased gradually, although that accumulated in leaves treated with 100 and 250 $\mu \mathrm{M}$ anthranilate was still more than the control value. The decrease in avenanthramide $\mathrm{A}$ at high anthranilate concentrations is probably due to the toxicity of anthranilate. In contrast to anthranilate, L-phenylalanine applied to elicited oat leaves had no effect on the accumulation of avenanthramide A.

Changes in amounts of endogenous anthranilate were investigated in elicitor-treated leaves. In 


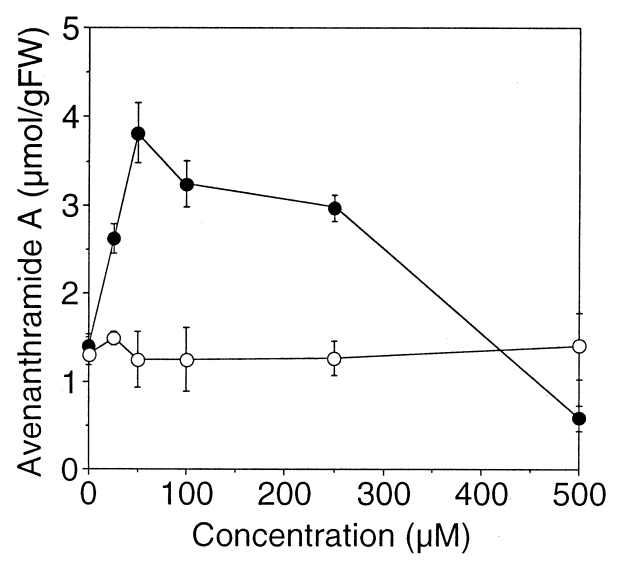

Fig. 3. Effects of exogenous application of anthranilate and L-phenylalanine on the avenanthramide accumulation. Oat leaf segments were floated on the $1 \mathrm{~mm}$ penta$\mathrm{N}$-acetylchitopentaose solution containing various concentrations of anthranilate (closed circle) and L-phenylalanine (open circle). After a 24-h incubation, amounts of avennanthramide A were determined. Each result is expressed as the mean of triplicate experiments \pm SD.

feshly excised leaves, only a small amount of anthranilate was present $(22.3 \mathrm{pmol} / \mathrm{g} \mathrm{FW})$. After elicitation, the amount did not change significantly even when AS activity reached a maximum. In addition, the amounts of anthranilate in elicitortreated leaves were not significantly different from those in control leaves.

\section{Discussion}

The dependencies of AS induction on the size and concentration of the elicitors were similar to those reported for the accumulation of avenanthramides (Ishihara et al., 1998) and the induction of other biosynthetic enzymes such as HHT, 4-coumarate: CoA ligase, cinnamate-4-hydroxylase, and phenylalanine ammonia-lyase (Ishihara et al., 1998; 1999b). These findings indicate that the induction of AS activity is part of the biochemical change required for avenanthramide synthesis in elicitor-treated leaves, and that the hydroxyanthranilate moieties of avenanthramides are supplied by the main track of the shikimate pathway by increase of the metabolic flow into the anthranilate branch on activation of AS.

AS has been indicated to consist of two subunits, the larger being AS $\alpha$ and the smaller AS $\beta$, in plants (Poulsen et al., 1993; Bohlmann et al.,
1995) and microorganisms (Crawford, 1989). AS $\alpha$ catalyzes the conversion of chorismate to anthranilate with ammonia as the amino donor, while AS $\beta$ has glutamine amido transferase activity. Since glutamine-dependent AS activity was strictly coeluted with ammonia-dependent activity, and the ratio of glutamine-dependent to ammonia-dependent activity remained unchanged during purification, the AS purified from elicitor-treated oat leaves probably contained both $\alpha$ and $\beta$ subunits. The complexity of the enzyme was also implied by the large molecular weight of the purified AS (around $113 \mathrm{kDa}$ ) determined by gel filtration: reported molecular weights of AS $\alpha \beta$ complexes range from $77 \mathrm{kDa}$ in Ailanthus altissima (Romero et al., 1996) to $220 \mathrm{kDa}$ in Ruta graveolens (Hertel et al., 1991). No chromatographic fractions had ammonia-dependent activity without glutaminedependent activity. As suggested for AS from $\mathrm{Ca}$ tharanthus roseus (Poulsen et al., 1993), the dissociation of AS subunits might have resulted in the inactivation of the enzyme.

In all plants species investigated, at least one AS isozyme was found to be feedback-sensitive (Poulsen and Verpoorte, 1991). The existence of a feedback-insensitive AS was reported in $R$. graveolens (Bohlmann et al., 1996) and tobacco (Song et al., 1998). The L-tryptophan concentrations required for $50 \%$ inhibition of feedback-sensitive AS were reported to be in the order of $\mu \mathrm{M}$ (Poulsen et al., 1993; Bohlmann et al., 1996; Li and Last, 1996; Song et al., 1998), whereas the concentrations for feedback-insensitive enzymes in $R$. gravelens and tobacco were greater than $300 \mu \mathrm{M}$ (Bohlmann et al., 1996; Song et al., 1998). AS purified from elicitor-treated oat leaves was inhibited $50 \%$ by $5 \mu \mathrm{M}$ L-tryptophan, indicating that the elicitor-inducible AS is feedback-sensitive. AS from elicited oat leaves was also sensitive to known false feedback inhibitors, 5-methyl-DL-tryptophan, 5-fluoro-DL-trypthophan and 6-fluoro-DL-trypthophan, although completely resistant to 5-hydroxyDL-tryptophan and 3-indoleacrylic acid, weak inhibitors for AS in carrot (Widholm, 1972a) and tobacco (Widholm, 1972b). Since AS purified from intact oat leaves was inhibited by L-tryptophan and false feedback inhibitors, both elicitorinducible and constitutive AS activities in oats are considered to be feedback-sensitive. However, the constitutive AS was about 2-fold more sensitive to 
these inhibitors than the elicitor-inducible AS. The difference in sensitivity may imply that different isozymes occur in elicitor-treated and intact leaves, although no separation of isozymes was detected during purification.

Since the induction of AS activity was not affected by the application of L-tryptophan, the suppression of avenanthramide accumulation by $\mathrm{L}-$ tryptophan and 5-methyl-DL-tryptophan is attributable to feedback inhibition of AS by these compounds. In addition, exogenous application of Dtryptophan did not suppress the accumulation of avenanthramides. These findings confirm that the induction of feedback-sensitive AS is responsible for the production of avenanthramides.

The involvement of induction of a feedback-sensitive AS isozyme in the biosynthesis of secondary metabolites has been suggested in Arabidopsis (Niyogi and Fink, 1992; Zhao and Last, 1996). Since the expression of the gene encoding the feedback-sensitive AS $\alpha$ isozyme, ASA1, was induced by infection with a pathogen, the activation of ASA1 has been related to the production of defensive secondary metabolites, indole glucosinolates and camalexin. On the other hand, in $R$. graveolens, the inducible AS isozyme involved in the production of acridone and furoquinoline alkaloids has been indicated to be feedback-insensitive (Bohlmann et al., 1996). This difference may be explained by the biosynthetic pathways for the secondary metabolites in the respective species. The acridone and furoquinoline alkaloids in $R$. graveolens are synthesized from anthranilate without the formation of tryptophan (Tsuji et al., 1993), whereas the indole glucosinolates in Arabidopsis have been indicated to originate from tryptophan (Baumert et al., 1983). The feedback regulation from tryptophan may thus operate in the biosynthesis of secondary metabolites in Arabidopsis. However, since oat phytoalexins, avenanthramides, are synthesized from anthranilate directly, seemingly a feedback is not essential. The sensitivity to L-tryptophan may be an original property of AS, and have remained unchanged after AS was recruited for the biosynthesis of avenanthramides. Alternatively, elicitor-inducible AS may be involved in the biosynthesis of unknown tryptophan-derived secondary metabolites in addition to avenanthramides.

Exogenous application of anthranilate resulted in the enhanced production of avenanthramides. Accordingly, AS may play a role as a rate-limiting enzyme in the biosynthesis of avenanthramides. AS has also been suggested to be a rate-limiting enzyme in the biosynthesis of tryptophan (Delmer and Mills, 1968; Widholm, 1974). Since anthranilate is cytotoxic at mu concentration (Schmauder and Roos, 1987), maintaining a low concentration of endogenous anthranilate seems to be important for plants. 
Baumert A., Kuzovkina I. N., Hieke M. and Gröger D. (1983), Biosynthesis of rutacrydone: The N-methylation step. Planta Med. 48, 142-144.

Bohlmann J., De Luca V., Eilert U. and Martin W. (1995), Purification and cDNA cloning of anthranilate synthase from Ruta graveolens: Modes of expression and properties of native and recombinant enzymes. Plant J. 7, 491-501.

Bohlmann J., Lins T., Martin W. and Eilert U. (1996), Anthranilate synthase from Ruta graveolens. Plant Physiol. 111, 507-514.

Bordin A. P. A., Mayama S. and Tani T. (1991), Potential elicitors for avenalumin accumulation in oat leaves. Annu. Phytopath. Soc. Japan 57, 688-695.

Bradford M. M. (1976), A rapid and sensitive method for the quantitation of microgram quantities of protein utilizing the principle protein-dye binding. Anal. Biochem. 72, 248-254.

Bücker C., Witte B., Windmüller U. and Grambow H. J. (1995), Anthranilate synthase and chorismate mutase activities in stem rust-inoculated and elicitor-treated resistant, moderately resistant, and susceptible nearisogenic wheat lines. Z. Naturforsch. 50c, 54-60.

Crawford I. P. (1989), Evolution of a biosynthetic pathway: The tryptophan paradigm. Annu. Rev. Microbiol. 43, 567-600

Delmer D. P. and Mills S. E. (1968), Tryptophan biosynthesis in cell cultures of Nicotiana tabacum. Plant Physiol. 43, 81-87.

Hertel S. C., Hieke M. and Gröger D. (1991), Anthranilate synthase from Ruta graveolens: Partial purification and properties. Biochem. Physiol. Pflanzen 187, $121-129$.

Ishihara A., Matsukawa T., Miyagawa H., Ueno T., Mayama S. and Iwamura H. (1997), Induction of hydroxycinnamoyl-CoA: hydroxyanthranilate $N$-hydroxycinnamoyltransferase (HHT) activity in oat leaves by victorin C. Z. Naturforsch. 52 c, 756-760.

Ishihara A., Miyagawa H., Matsukawa T., Ueno T., Mayama S. and Iwamura H. (1998), Induction of hydroxyanthranilate hydroxycinnamoyl transferase activity by oligo- $N$-acetylchitooligosaccharides in oats. Phytochemistry 47, 969-974.

Ishihara A., Ohtsu Y. and Iwamura H. (1999a), Induction of biosynthetic enzymes for avenanthramides in elicitor-treated oat leaves. Planta 208, 512-518.

Ishihara A., Ohtsu Y. and Iwamura H. (1999b), Biosynthesis of oat avenanthramide phytoalexins. Phytochemistry 50, 237-242.

Li J. and Last R. L. (1996), The Arabidopsis thaliana trp5 mutant has a feedback-resistant anthranilate synthase and elevated soluble tryptophan. Plant Physiol. 110, $51-59$.
Mayama S., Matuura Y., Iida H. and Tani T. (1982), The role of avenalumin in the resistance of oat to crown rust, Puccinia coronata f. sp. avenae. Physiol. Plant Pathol. 20, 189-199.

Mayama S., Tani T., Matsuura Y., Ueno T. and Fukami H. (1981), The production of phytoalexins by oat (Avena sativa) in response to crown rust, Puccina coronata $\mathrm{f}$. $\mathrm{sp}$. avenae. Physiol. Plant Pathol. 19, 217-226.

Niyogi K. K. and Fink G. R. (1992), Two anthranilate synthase genes in Arabidopsis: defense-related regulation of the tryptophan pathway. Plant Cell 4, 421-433.

Niyogi K. K., Last R. L., Fink G. R. and Keith B. (1993), Supressors of trp1 fluorescence identify a new Arabidopsis gene, TRP4, encoding the anthranilate synthase $\beta$ subunit. Plant Cell 5, 1011-1027.

Poulsen C., Bongaerts R. J. M. and Verpoorte R. (1993), Purification and characterization of anthranilate synthase from Catharanthus roseus. Eur. J. Biochem. 212, $431-440$.

Poulsen C. and Verpoorte R. (1991), Roles of chorismate mutase, isochorismate synthase and anthranilate synthase in plants. Phytochemistry 30, 377-386.

Romero R. M. and Roberts M. F. (1996), Anthranilate synthase from Ailanthus altissima cell suspension cultures. Phytochemistry 41, 395-402.

Schmauder H. P. and Roos W. (1987), Regulation von Schlüsselenzymen der Biosynthese aromatischer Aminosäuren in alkaloidbildenden Kulturen von Penicillium cyclopium W. J. Basic Microbiol. 27, 583-594.

Song H.-S., Brotherton J. E., Gonzales R. A. and Widholm J. M. (1998), Tissue culture-specific expression of a naturally occurring tobacco feedback-insensitive anthranilate synthase. PlantPhysiol. 117, 533-543.

Tsuji J., Zook M., Somerville S. C. and Last R. L. (1993), Evidence that tryptophan is not a direct biosynthetic intermediate of camalexin in Arabidopsis thaliana. Physiol. Mol. Plant Pathol. 43, 221-229.

Widholm J. M. (1972a), Anthranilate synthase from 5methyltryptophan-susceptible and -resistant cultured Daucus carota cells. Biochim. Biophys. Acta 279, 48-57.

Widholm J. M. (1972b), Tryptophan biosynthesis in Nicotiana tabacum and Daucus carota cell cultures: Site of action of inhibitory tryptophan analogs. Biochim. Biophys. Acta 261, 44-51.

Widholm J. M. (1974), Control of aromatic amino acid biosynthesis in cultured plant tissues: Effect of intermediates and aromatic amino acids on free levels. Physiol. Plant. 30, 13-18.

Zhao J. and Last R. L. (1996), Coordinate regulation of the tryptophan biosynthetic pathway and indolic phytoalexin accumulation in Arabidopsis. Plant Cell 8, $2235-2244$ 